\title{
Procedimentos de limpeza aplicados na conservação de ladrilhos de marmorite do início do século $X X$
}

\author{
Cleaning procedures applied to the conservation of \\ terrazzo tiles from the early twentieth century
}

\section{Brena Tavares Bessa \\ Thais Alessandra Bastos Caminha Sanjad \\ Carolina de Souza Leão Macieira Gester}

\section{Resumo}

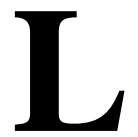

adrilhos de marmorite são constituídos por argamassas pigmentadas compostas de agregado mineral moído, cimento (normal, branco ou pigmentado) e areia. O agregado mineral é denominado granitina, responsável pelo efeito decorativo das peças. Em Belém, PA,

Brasil, a origem da utilização desses ladrilhos data do início da importação de materiais de construção no contexto da industrialização. Os ladrilhos de marmorite são alvo das ações intempéricas e antrópicas que resultam em diversas anomalias, cujo tratamento depende das especificidades de seus constituintes. O objetivo deste trabalho é verificar a eficácia das técnicas de limpeza mecânica com água e sabão neutro, emplastro químico de bentonita e laser nas amostras de ladrilho de marmorite de cimento. Nos resultados obtidos por meio de medições de brilho e cor após diagnóstico por avaliação visual, a limpeza a laser apresentou resultados superiores, especialmente nas cores branco, preto e rosa. Entretanto, a técnica causou modificações nas propriedades de brilho do material. Já o emplastro de bentonita obteve resultados satisfatórios, especialmente na cor verde, sem provocar alterações no brilho das amostras. A pesquisa visa iniciar estudos de aplicação do laser em ladrilhos de marmorite para que, posteriormente, a técnica torne-se viável para outros produtos similares, de origem calcária e cimentícia.

Palavras-chave: Material cimentício. Conservação. Laser. Bentonita. Cor. Brilho.

\begin{abstract}
Terrazzo tiles are made of crushed mineral aggregate, cement (normal, white or pigmented) and sand. The mineral aggregate, called granitine, is responsible for the tiles' decorative appearance. The origin of its use in buildings in the city of Belem (Brazil) dates back to the start of imports of

building materials during Brazilian industrialisation period. Terrazzo tiles are subject to weathering and human action, which cause several anomalies whose treatment depends on the tiles' constituents. The objective of this study is to evaluate the effectiveness of mechanical cleaning techniques using water and neutral soap, chemical bentonite patches and laser on terrazzo tile samples. After a visual analysis, the efficacy of the different methods was evaluated through brightness and colour measurements. The results showed that the laser cleaning yielded superior results, especially in the white, black and pink colours. However, the technique caused changes in the brightness of the tiles. The bentonite patch achieved satisfactory overall results, especially in the green colour, without causing changes in the brightness of the samples. This study aims to improve cleaning strategies so that, subsequently, the technique becomes feasible for other similar products, as well as for limestone and cement-based materials.

Keywords: Cement based matrials. Conservation. Laser. Bentonite. Color. Brightness.
\end{abstract}

${ }^{1}$ Brena Tavares Bessa ${ }^{1}$ Universidade Federal do Pará Belém - PA - Brasil

${ }^{2}$ Thais Alessandra Bastos Caminha Sanjad ${ }^{2}$ Universidade Federal do Pará Belém - PA - Brasil

${ }^{3}$ Carolina de Souza Leão Macieira Gester ${ }^{3}$ Universidade Federal do Pará Belém - PA - Brasil

Recebido em 15/01/19

Aceito em 21/07/19 


\section{Introdução}

De origem italiana (Veneza), também denominados "terrazzos", os marmorites são argamassas pigmentadas compostas de agregado mineral moído, ligante - cal aérea ou cimento (normal, branco ou pigmentado) - e areia. Inicialmente aplicados nos pisos das áreas externas com a reutilização de resíduos de mármore, são formas simplificadas de antigos mosaicos de mármore de meados do século XV. O agregado mineral é atualmente denominado granitina, granilite ou granilha, responsável pelo efeito decorativo das peças (NATIONAL..., 2014).

O marmorite, por ser um material versátil, era utilizado na manufatura de peças diversificadas, desde escadarias, degraus, soleiras, peitoris, chapins, colunas, balaustradas, portais, lâminas para móveis, tampos para mesas, pias, sacadas para janelas, painéis e inúmeros padrões de ladrilhos de piso, até mausoléus e monumentos (Figura 1).

A Standard LS38:1966 define ladrilho de marmorite como uma peça “[...] composta por duas camadas ligadas, sendo a superior uma superfície lisa constituída geralmente de cimento branco e uma mistura predeterminada de fragmentos de mármore ou outra pedra e pó destes. A camada inferior constitui-se de cimento Portland, areia e agregado [...]” (LIBNOR, $1966^{1}$ apud KARAM; TABBARA, 2009).

O surgimento dos ladrilhos de marmorite como são conhecidos hoje é incerto. De acordo com a fábrica italiana Grandinetti, eles surgiram em 1800, paralelamente à invenção e início da utilização do cimento, utilizado como ligante para os fragmentos obtidos com a moagem de vários tipos de mármore (GRANDINETTI, 2015). Entretanto, tal narrativa é improvável, pois a cal aérea se caracterizava como o principal ligante das misturas até fins do século XIX. Após a generalização do uso do cimento Portland, surgiu o marmorite de cimento (MARTINHO; VEIGA; FARIA, 2018).

\section{Figura 1 - Exemplos produtos de marmorite}

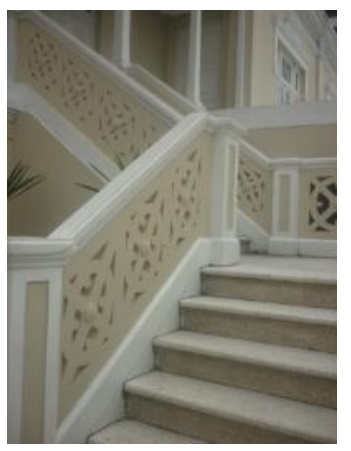

(a) Guarda-corpo e escadaria

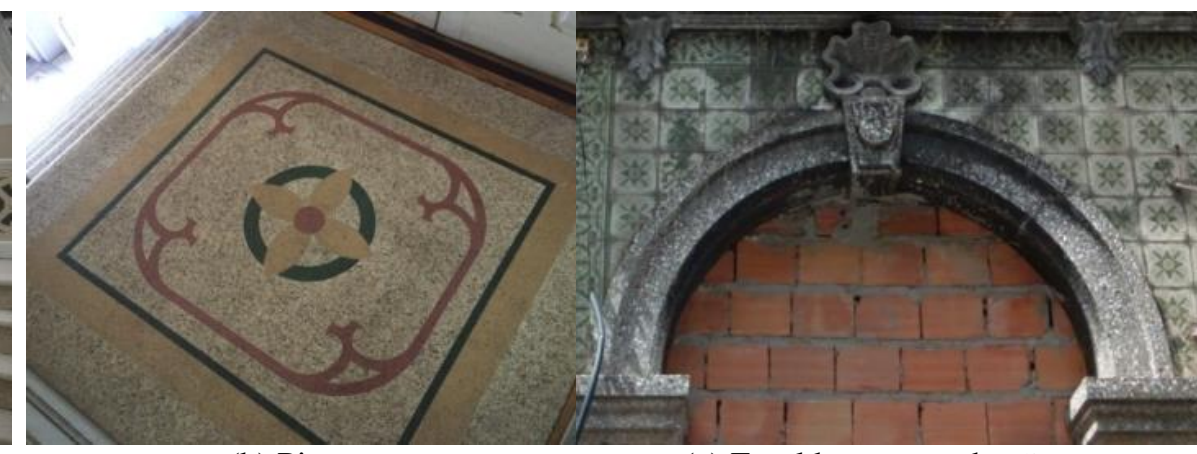

(b) Piso (c) Emolduramento de vão

Figura 2 - Padrões de ladrilhos de marmorite

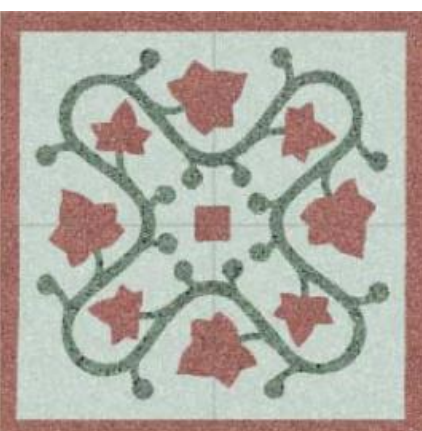

(a) Liberdade

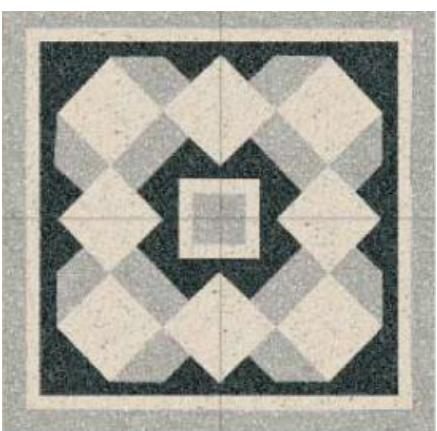

(b) Futurista

Fonte: Grandinetti (2015).

\footnotetext{
1LIBNOR, LS38 Terrazzo Tiles, Lebanese Standards Institution (1966), Getco Ctr., Sin El Fil, Lebanon. In: KARAM, G.; TABBARA, M.
} Properties of pre-cast terrazzo tiles and recommended specifications. Revista Cerâmica, v. 55, p. 84-87, 2009. 
Acredita-se que os primeiros ladrilhos na Itália foram produzidos em uma comunidade de monges em San Severino Marche, em Macerata. O local tornou-se nos anos 50 o centro da produção italiana de produtos de marmorite. No início do século XX, os ladrilhos produzidos apresentavam majoritariamente motivos florais, tendência denominada liberdade (Figura 2a). Posteriormente, nas décadas de 1930 e 1940, intensificou-se a utilização de ladrilhos com motivos geométricos, cuja tendência denominava-se futurista (Figura 2b) (GRANDINETTI, 2015).

Em Belém, a origem da utilização dos ladrilhos de marmorite nas edificações data do início da importação de materiais de construção no contexto da industrialização, já que diversos materiais pré-moldados eram importados por meio de catálogos em meados do século XIX. Considera-se, entretanto, que a produção local começou no século XX. Já o início da importação de cimento e agregados para a cidade iniciou-se no final do século XIX.

Os ladrilhos de marmorite apresentam manufatura análoga à do ladrilho hidráulico (Figura 3). Supõe-se que, assim como os ladrilhos hidráulicos, os ladrilhos de marmorite eram fabricados de maneira semiartesanal, com o auxílio de prensa. Inicialmente, era utilizada a prensa mecânica do tipo parafuso. Um número restrito de fábricas utilizava a prensa hidráulica.

O processo inicia-se com o derramamento da mistura de cimento Portland ou branco, pigmento, areia e/ou pó de pedra e granitina no molde previamente untado com óleo desmoldante. Cada mistura é depositada individualmente no local correspondente de acordo com a decoração que se pretende ter como resultado. Em virtude da técnica artesanal, essa camada apresenta espessura variável. Em seguida, o gabarito é retirado para o depósito de uma fina camada "secante" - composta de cimento cinza puro em pó - com a função de endurecer a mistura e impedir que as cores se misturem.

A camada seguinte, mais espessa, corresponde ao tardoz do ladrilho de marmorite, é composta de cimento Portland, areia e água, na forma de argamassa. Depositado o material na forma, segue-se à compactação com prensa e posterior adição de água para umedecer a mistura correspondente ao tardoz. Depois do ladrilho moldado e prensado, ele passa pelo processo de secagem ao ar livre, por $24 \mathrm{~h}$. A cura do material poderia ser feita com imersão em água ou continuar o processo ao ar. Ao final, a face decorada do ladrilho é polida para que as granitinas obtenham um aspecto reluzente.

Os ladrilhos de marmorite são alvo das ações intempéricas e antrópicas que resultam nas anomalias observadas nas peças. Uma das consequências da exposição em edifícios históricos a esses agentes ambientais é o escurecimento da superfície devido à sujidade (CARMONA-QUIROGA et al., 2010). Royo et al. (1998) destacam as principais anomalias observadas nos ladrilhos de marmorite (Figura 4).

O tratamento do ladrilho de marmorite difere a partir das especificidades de seus constituintes. No entanto, o estudo de técnicas já aplicadas em materiais análogos e de seus princípios norteadores auxilia na determinação de técnicas específicas. No caso de marmorites de cimento Portland, misturas altamente básicas ou ácidas podem causar a dissolução do material. Sabões oleosos podem ocasionar a descoloração do marmorite e impregnar maior quantidade de sujidade. Os sais e depósitos carbonáticos podem formar um filme na superfície de materiais calcários (CHABBI, 2004).

\section{Figura 3 - Manufatura de ladrilhos hidráulicos}

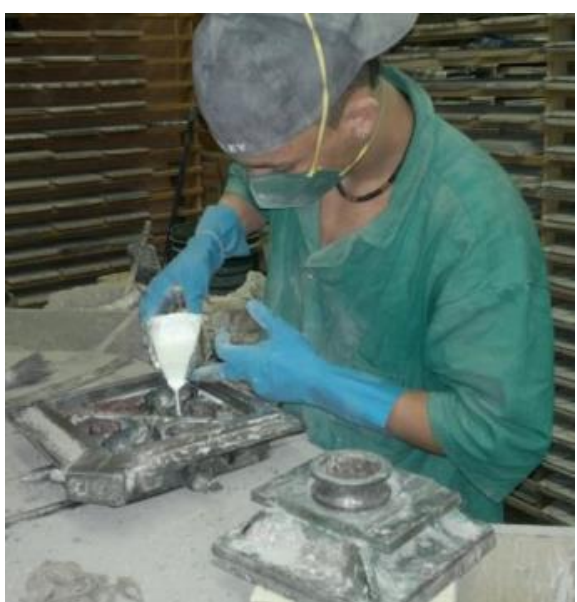

(a) Derramamento da mistura no molde

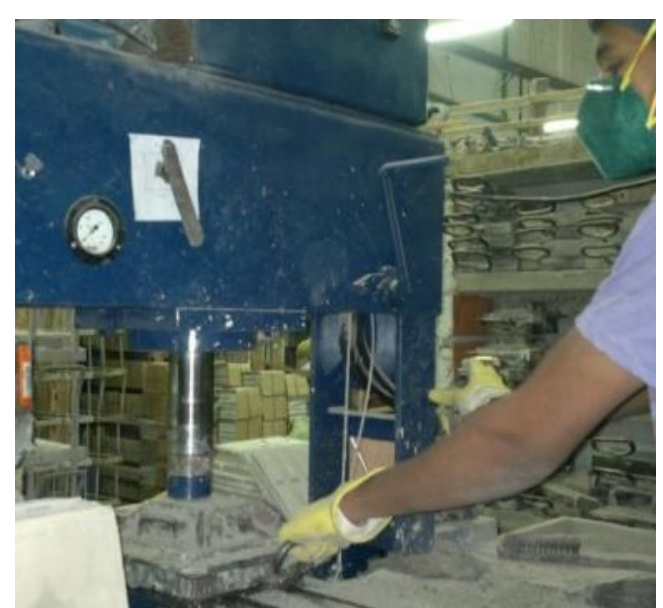

(b) Operário manuseando a prensa hidráulica 
Figura 4 - Exemplos de anomalias encontradas nos pisos de marmorite de Belém, PA, Brasil

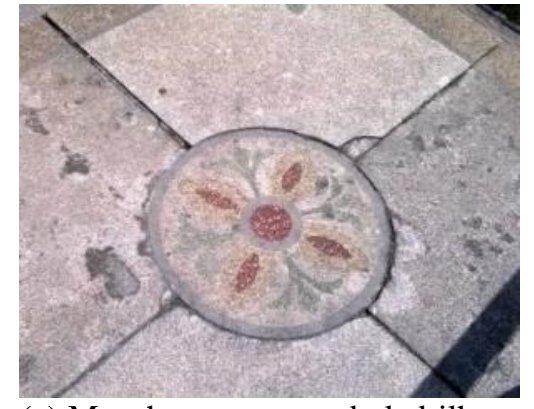

(a) Manchas no centro do ladrilho e nas proximidades das juntas de assentamento e enegrecimento e abertura das juntas

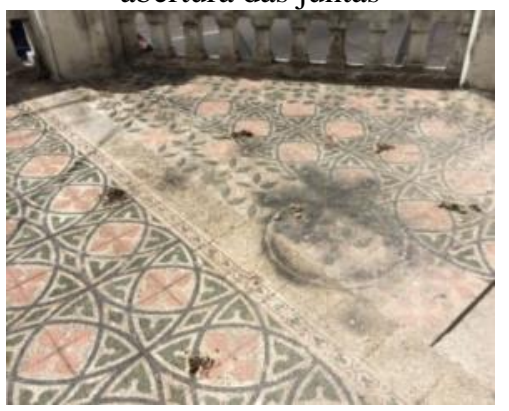

(d) Descoloração e mudança de tons nos ladrilhos

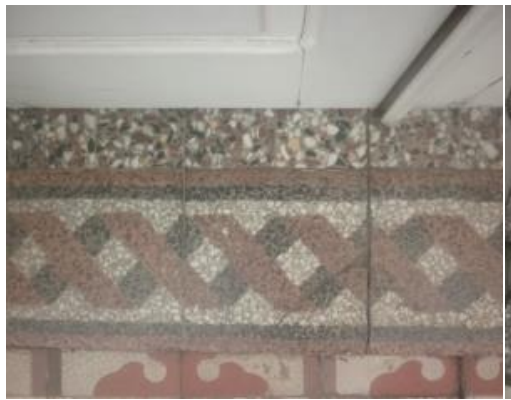

(b) Afundamento dos ladrilhos entre $1 \mathrm{~mm}$ e $2 \mathrm{~mm}$, protuberâncias e depressões

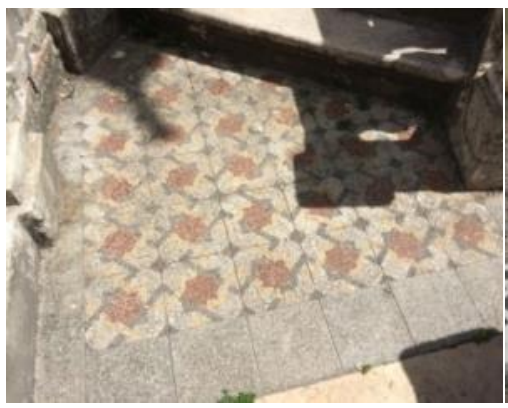

(e) Perda da matriz e

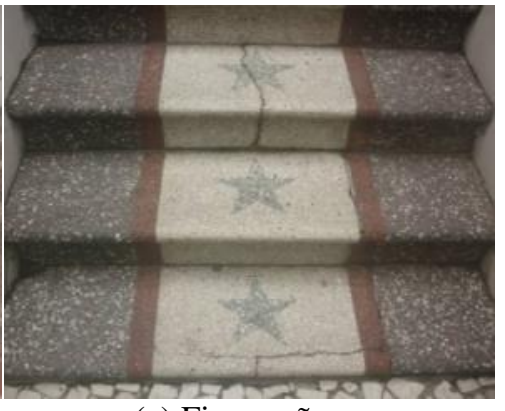

(c) Fissuração destacamento do agregado no centro e nas arestas, aspereza

Estudos de limpeza em marmorite de cal demonstraram eficácia na utilização de emplastros químicos (pasta de celulose e bicarbonato de amônio), por via úmida, com jatos de água a baixa pressão, e limpeza a seco por meio de microabrasão com farinha de sílica (IN SITU, 2006).

Emplastros de bentonita são usados na limpeza de rochas (OLIVEIRA, 2011). O ladrilho de marmorite apresenta composição semelhante à de rochas calcáreas, já que estas são aí utilizadas como agregado.

A limpeza por laser (Light Amplification by Stimulated Emission of Radiation), em contrapartida, é um procedimento utilizado na remoção de manchas enegrecidas em superfícies frágeis, ou naquelas em que os danos são pontuais, em que se requer intervenção mínima. O laser é uma fonte única de energia controlável. Os sistemas de limpeza utilizados na conservação emitem pulsos curtos de luz infravermelha com comprimento de onda tal que tende a ser absorvido por depósitos de sujidade, entre outros contaminantes, da superfície dos materiais. A energia absorvida pela camada converte-se em calor responsável por ejetar da superfície as partículas depositadas (LYNTON LASERS LTD). A limpeza a laser em edificações históricas tem sido restrita a detalhes arquitetônicos e artísticos. Apesar de métodos considerados mais rápidos e baratos serem preferíveis para grandes dimensões, a utilização do laser em áreas externas aumentou consideravelmente na Europa (COOPER, 2005).

Este artigo avalia a eficácia de três técnicas de limpeza - limpeza mecânica com água e sabão neutro, emplastro químico de bentonita e laser - em amostras de ladrilhos de marmorite de cimento datados do início do século XX que estavam em áreas expostas, sujeitos às ações intempéricas e antrópicas. A avaliação foi feita por meio de medições de brilho e cor, já que tais propriedades são facilmente alteradas por meio do intemperismo e de limpezas inadequadas.

\section{Materiais e métodos}

O artigo avalia os resultados de dois procedimentos de limpeza aplicados em amostras de ladrilhos de marmorite utilizados em edificações na cidade de Belém, PA, com base em propriedades físicas. 
A amostragem é composta de três amostras de ladrilhos de marmorite inteiros, datados do início do século XX, em dimensões 20x20 cm (Figura 5). Todas as amostras foram coletadas de edificação localizada na Vila Bolonha, no bairro de Nazaré, em Belém.

Primeiramente, procedeu-se ao mapeamento de danos das amostras. Estas foram fotografadas, e os danos foram documentados por meio do software AutoCAD. A legenda de identificação dos danos foi adaptada de estudos de Chabbi (2004) e Veiga, Tavares e Magalhães (2007) sobre diagnóstico de marmorites de cimento Portland e de cal.

As amostras de ladrilhos inteiros foram submetidas previamente a observação visual de anomalias, cor e brilho, e a medições quantificadas de cor e brilho. As cores foram classificadas com o auxílio de colorímetro, modelo CR-400, da Konica Minolta, do Laboratório de Materiais Dentários da Faculdade de Odontologia da Universidade Federal do Pará (UFPA). Os resultados são fornecidos utilizando-se a escala CIE L*a*b. O eixo $\mathrm{L}$, que representa o difusor de branco, varia de 0 a 100; o eixo A varia do positivo (tendência ao vermelho) ao negativo (tendência ao verde); e o eixo B varia do positivo a amarelo ao negativo a azul. Os valores finais foram comparados mediante seus deltas $(\Delta): \Delta \mathrm{L}$ (diferença em mais claro e mais escuro); $\Delta \mathrm{a}$ (diferença em vermelho e verde); $\Delta \mathrm{b}$ (diferença em amarelo e azul); e $\Delta \mathrm{E}$, que corresponde à diferença total de cor (KONITA..., 2016). O $\Delta \mathrm{E}$ é calculado com a seguinte fórmula (Equação 1):

$\Delta E=\left[\Delta L^{2}+\Delta a^{2}+\Delta b^{2}\right] 1 / 2$

Onde:

$\Delta \mathrm{L}=\mathrm{L}_{2}-\mathrm{L}_{1}$;

$\Delta \mathrm{a}=\mathrm{a} *_{2}-\mathrm{a}_{1}$; ; nd

$\Delta \mathrm{b}=\mathrm{b}^{*}{ }_{2}-\mathrm{b} *_{1}$.

As medições de brilho ocorreram com a adoção do Portable Gloss Meter do Modelo GMS, da SADT, pertencente ao Laboratório de Conservação, Restauração e Reabilitação (Lacore/UFPA). Os resultados são fornecidos em unidades de brilho, no ângulo de $60^{\circ}$.

\section{Figura 5 - Mapa de amostras}

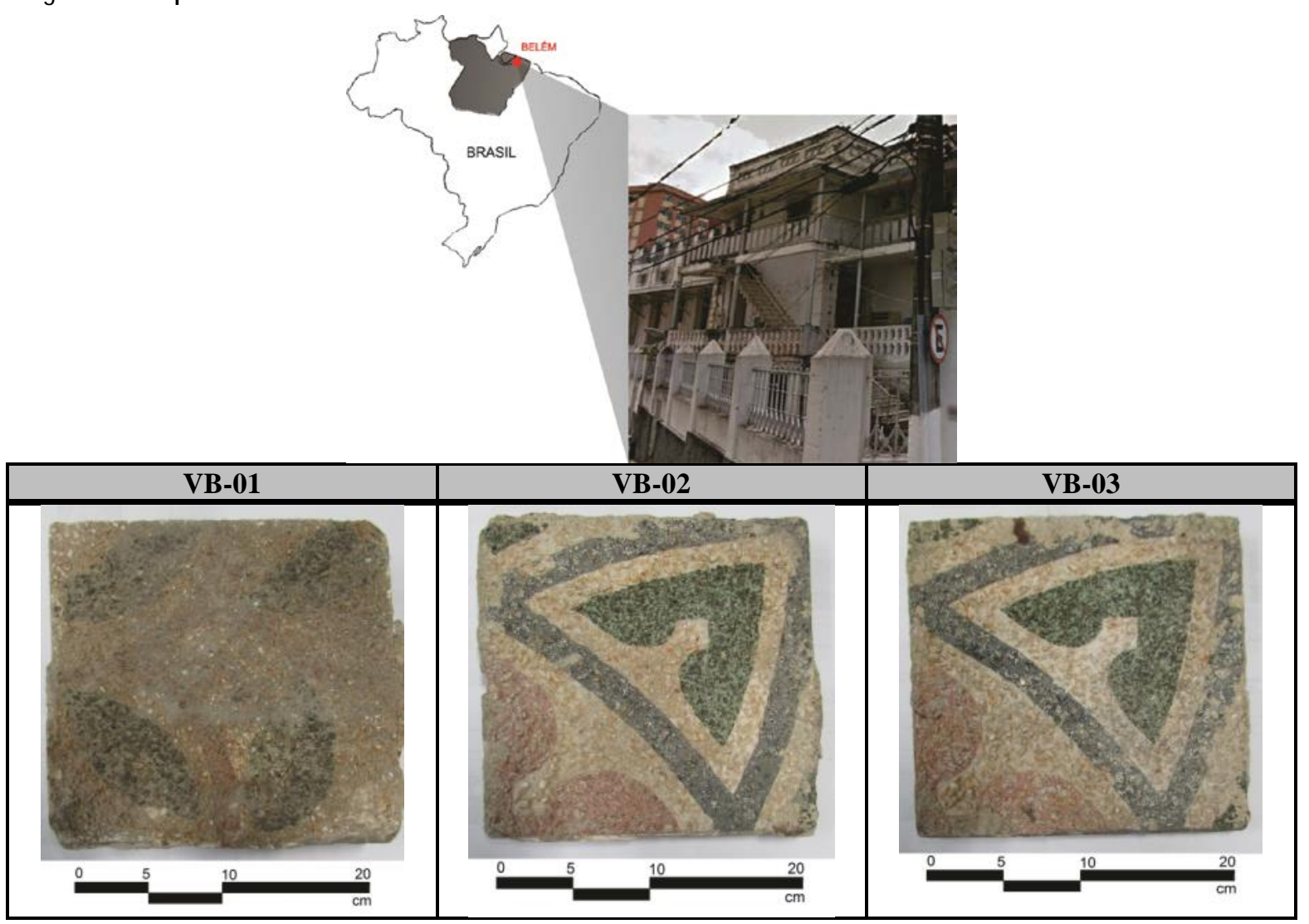


Em seguida, os ladrilhos foram higienizados com água destilada e sabão neutro, pH=7, e colocados em estufa por $2 \mathrm{~h}$ à temperatura de $60{ }^{\circ} \mathrm{C}$ para secagem. As amostras foram submetidas novamente às medições, para verificação da ação da limpeza por via úmida.

Com o objetivo de verificar o procedimento mais eficaz na remoção de sujidades persistentes, manchas e demais depósitos nos ladrilhos, estes foram fracionados em três faixas - à esquerda, área sem aplicação; ao centro, aplicação de laser; e à direita, aplicação de bentonita. Após a aplicação dos dois métodos de limpeza, ocorreram medições de brilho e cor como ferramenta para balizar os resultados obtidos.

A limpeza dos ladrilhos foi realizada com aparelho Compact Phoenix Conservation Laser Cleaning System, da Lynton Conservation, do tipo Nd:YAG, comprimento de onda de 1.064/532 nm, frequência de repetição de 1-30 Hz, comprimento do pulso maior que 5 ns. Na aplicação, o comprimento de onda utilizado foi de $1.064 \mathrm{~nm}$, e a frequência de repetição, de $15 \mathrm{~Hz}$.

Já a bentonita consiste em um tipo de argila composta majoritariamente pelo mineral montmorilonita, do grupo das esmectitas (Figura 6). Sua principal característica, além da plasticidade, é a capacidade de expansão quando em contato com a água. Quando se trata de uma bentonita sódica, a expansão é acentuada (LUZ; OLIVEIRA, 2008).

A pasta aplicada baseia-se nas recomendações de Oliveira (2011) sobre a metodologia de limpeza de rochas por meio de emplastros com argilas absorventes. Contém bentonita (123,91 g), bicarbonato de sódio $\left(\mathrm{NaHCO}_{3}\right)(10 \mathrm{~g})$, ácido etilenodiamino tetra-acético (EDTA) (12,50 g) e ácido acético $\left(\mathrm{CH}_{3} \mathrm{COOH}\right)(5 \mathrm{ml})$. O emplastro deve apresentar $\mathrm{pH}$ neutro, devidamente aferido no momento da aplicação (OLIVEIRA, 2011). O emplastro foi aplicado nas peças com o auxílio de uma espátula metálica, e cobriu-se o ladrilho com papel alumínio e plástico-filme, para que a pasta permanecesse úmida por mais tempo. Retirou-se o emplastro nos intervalos de 7, 10 e 13 dias - com a utilização de espátula metálica e água -, objetivando observar a eficiência da limpeza no decorrer do tempo. Estudos com pasta de bentonita na limpeza de rochas carbonáticas mostrou que a ação do material inicia-se a partir do sétimo dia de permanência do material aplicado.

\section{Resultados e discussões}

\section{Diagnóstico e avaliação visual da limpeza}

Os danos observados nas peças em estado original são perda de coesão do agregado, erosão da matriz cimentícia, alteração de cor, depósitos de argamassa de assentamento, manchas amareladas no agregado, manchas de corrosão de metal e depósito de sujidade (Figura 7). Ladrilhos de marmorite não apresentam ligas metálicas em sua composição - acredita-se que as manchas encontradas têm origem externa ao ladrilho. A argamassa encontrada é oriunda do processo de assentamento das peças. Outros estudos mostram que fissuras, fraturas, pintura e colonização biológica por vegetais superiores são os principais danos encontrados em ladrilhos de marmorite instalados em piso (CHABBI, 2004), enquanto em argamassas de marmorite de fachada, de cal, encontram-se manchas de sujidade, colonização biológica, fendilhação, fissuração, perda de aderência (descolamentos, abaulamentos, destacamentos), perda de coesão e erosão (VEIGA; TAVARES; MAGALHÃES, 2007).

Figura 6 - Difratograma da bentonita sódica aplicada

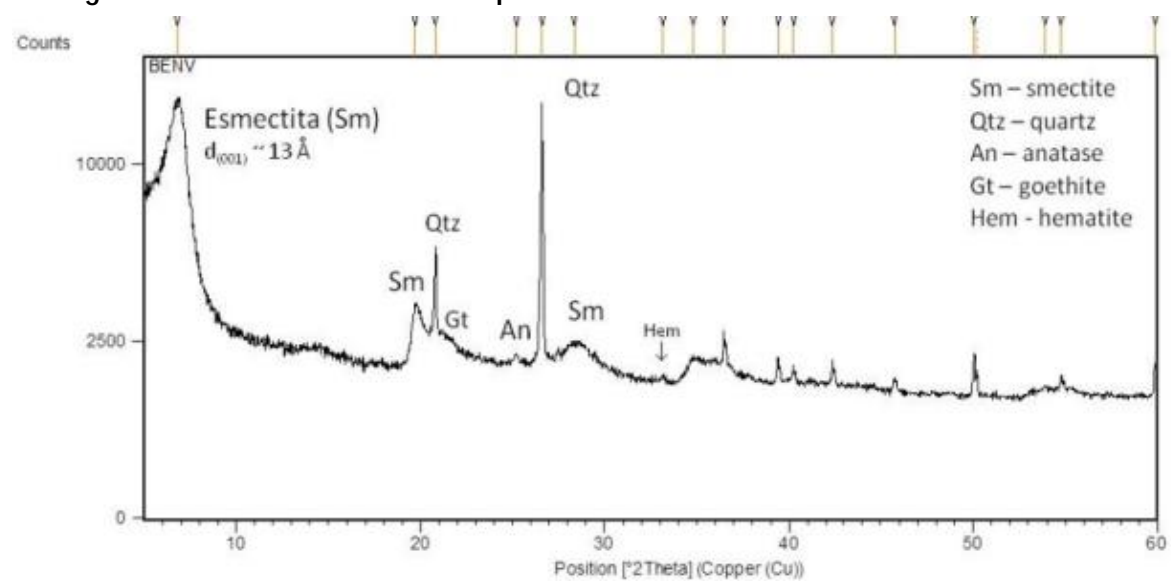

Fonte: Loureiro (2013) 
Figura 7 - Mapeamento de danos antes dos procedimentos de limpeza

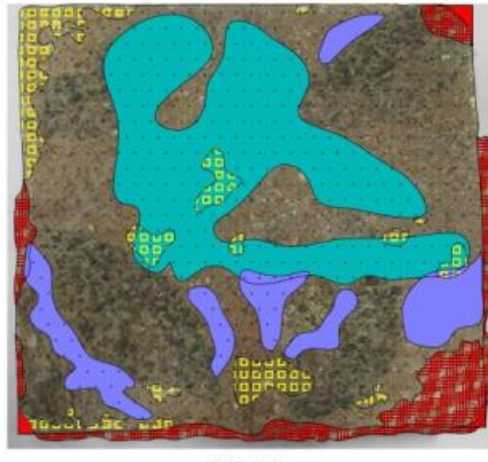

VB-01

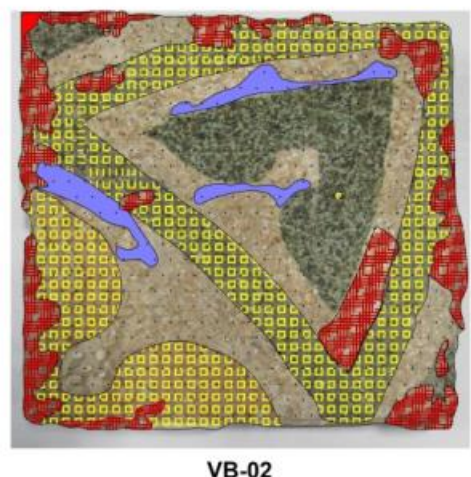

VB-02
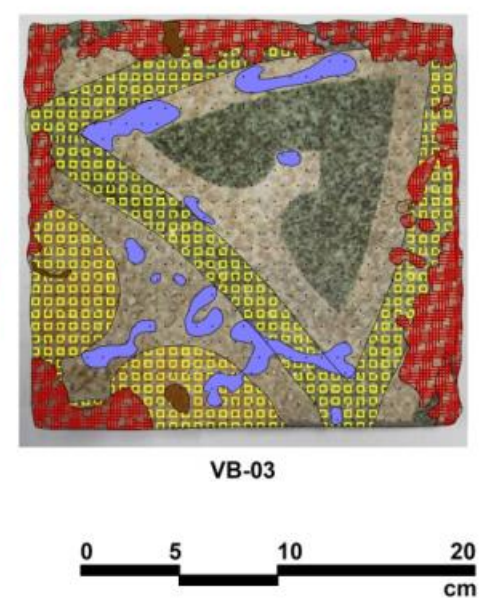

LEGENDA

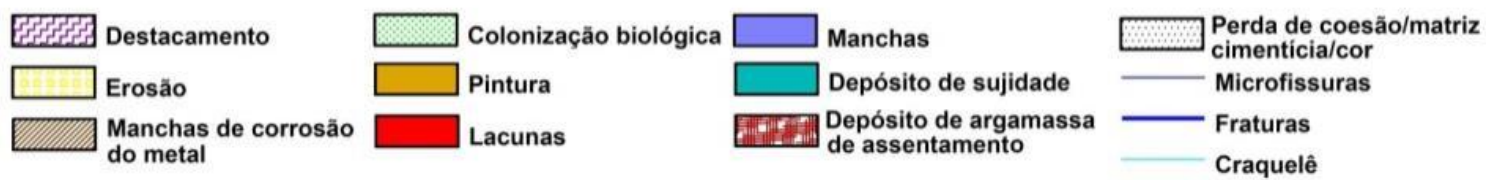

Fonte: adaptada de Chabbi (2004) e Veiga, Tavares e Magalhães (2007).

A limpeza por via úmida sanou os danos devidos à sujidade na amostra VB-01, a tempo em que evidenciou outros danos, como manchas e depósitos de argamassa anteriormente imperceptíveis. Já a limpeza física na amostra VB-01 (Figura 9), com aplicação de laser na faixa 2, e a química, com utilização de emplastro de bentonita na faixa 3, sanaram outros danos identificados. A limpeza a laser removeu o depósito de sujidade e destacou as cores da faixa correspondente (faixa 2). Enquanto isso, na faixa 3, a aplicação de emplastro de bentonita diminuiu as manchas mencionadas, entretanto em menor intensidade do que o laser. Com relação ao tempo de aplicação do emplastro, a diferença visual ocasionada pela permanência do material durante 7, 10 ou 13 dias é discreta.

As amostras VB-02 (Figura 10) e VB-03 apresentaram resultados semelhantes, evidenciando poucas mudanças após a limpeza por via úmida, já que os danos que essas amostras apresentavam requeriam procedimentos de limpeza de maior penetração e ação prolongada. O tratamento por laser mostrou-se algo eficaz nas áreas com pigmento preto, quando comparado com o existente nas faixas 1 e 3 . As áreas preta e rosa obtiveram uma cor mais acentuada, enquanto nas outras faixas a cor encontrava-se acinzentada. Na área branca, o laser diminuiu acentuadamente as manchas do agregado e da matriz; na área verde, os efeitos foram discretos. Os resultados foram menos perceptíveis com a aplicação do emplastro de bentonita. Tais observações foram ratificadas nos resultados dos ensaios de cor.

\section{Quantificação de brilho e cor}

Antes da limpeza por via úmida, as amostras apresentaram comportamento semelhante com relação ao brilho, variando entre 0,193 ub e 0,367 ub (unidades de brilho). Os materiais com valores de brilho inferiores a 10 ub são considerados superfícies opacas (CARMONA-QUIROGA et al., 2010). É o caso dos ladrilhos de marmorite analisados. Após a limpeza, do total de 9 faixas medidas, 5 apresentaram aumento no brilho, o que corresponde a 56\% das faixas. O aumento concentrou-se na amostra VB-01, que, conforme diagnóstico prévio, apresentava maiores depósitos de sujidade. Nas amostras VB-02 e VB-03 observou-se aumento de brilho em apenas uma das faixas. A diminuição de brilho, entretanto, não se mostrou acentuada.

Na amostra VB-01, após a limpeza por via úmida, todas as faixas apresentaram aumento dos índices de brilho: 2,77\% na faixa 1, 37,45\% na faixa 2, e 32,39\% na faixa 3. Após a limpeza química e mecânica (Figuras 8 e 9), as amostras demonstraram aumento de desempenho acumulado de 57,30\% com a aplicação do laser e de 48,58\% com a aplicação do emplastro de bentonita (Tabela 2). 
Figura 8 - Resultado obtido por meio da limpeza da amostra VB-01: estado original, após primeira limpeza por via úmida, após aplicação de laser (faixa 2) e emplastro de bentonita (faixa 3)

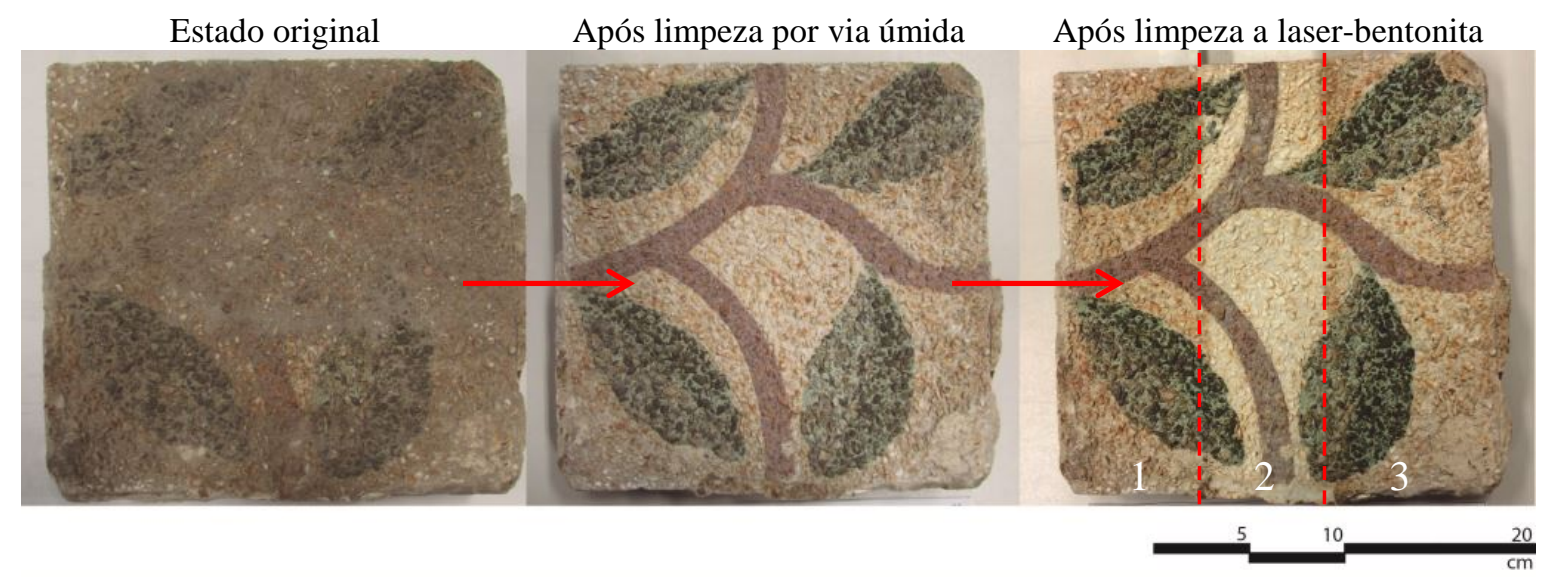

Figura 9 - VB-01 após procedimentos de limpeza

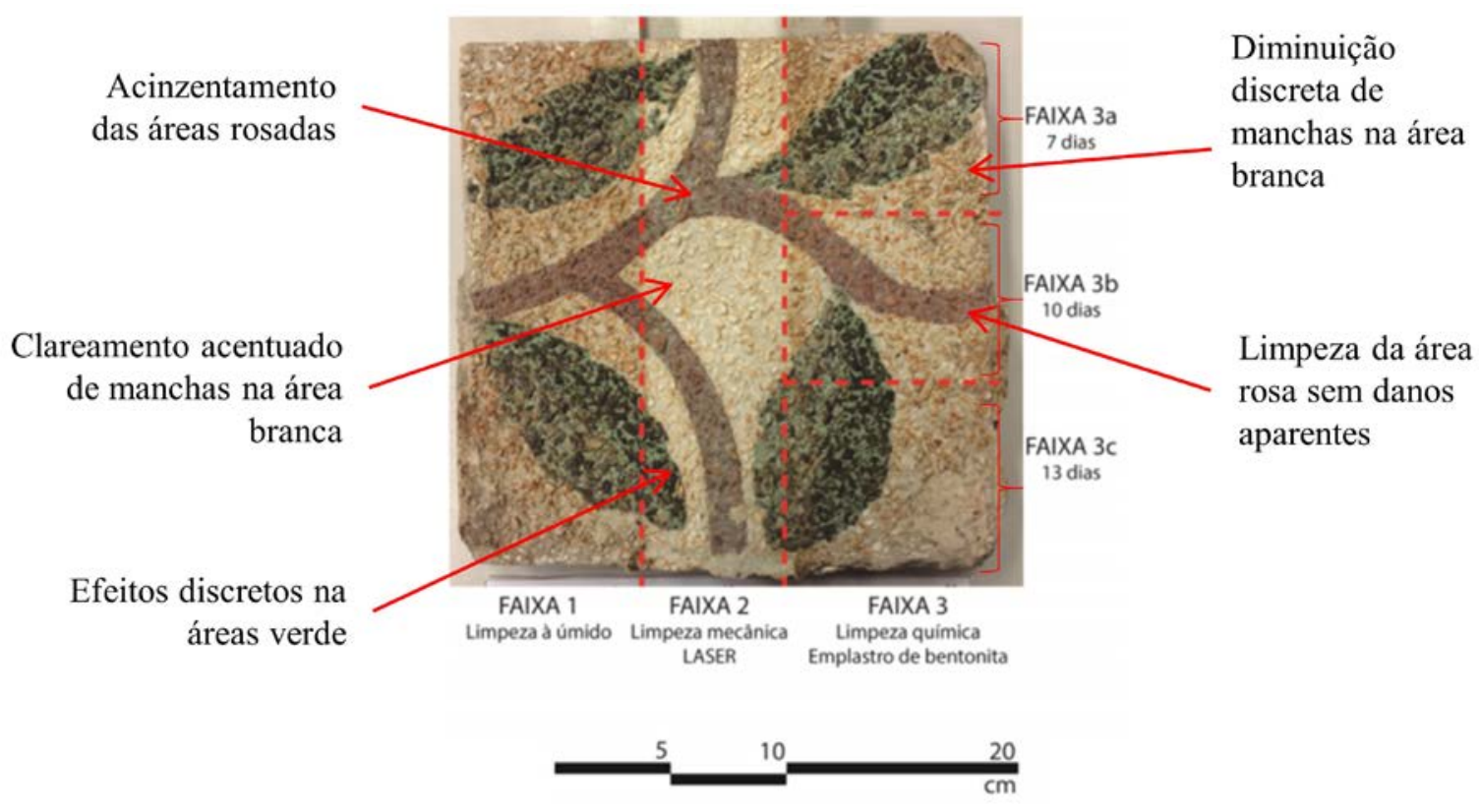

Figura 10 - Resultado obtido por meio da limpeza da amostra VB-02: estado original, após primeira limpeza por via úmida, após aplicação de laser (faixa 2) e emplastro de bentonita (faixa 3 )

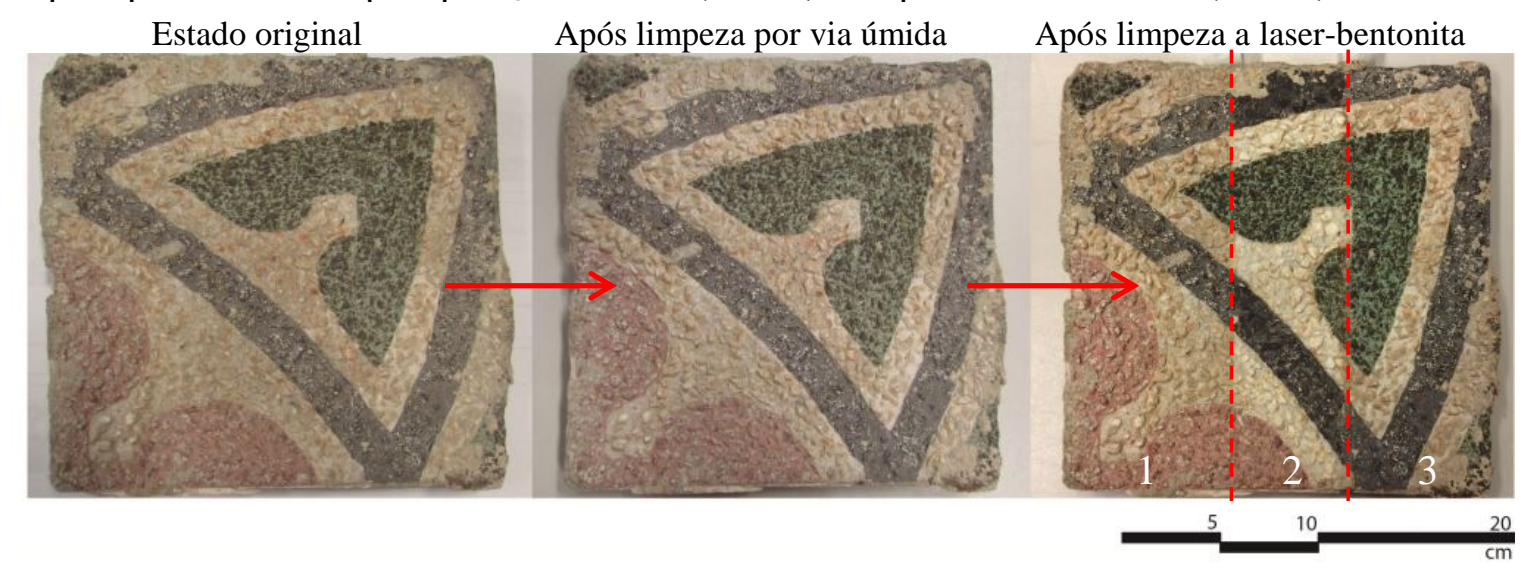


Figura 11 - VB-02 após procedimentos de limpeza - na faixa 3 mostra-se o resultado obtido com diferentes tempos de aplicação dos emplastros com bentonita

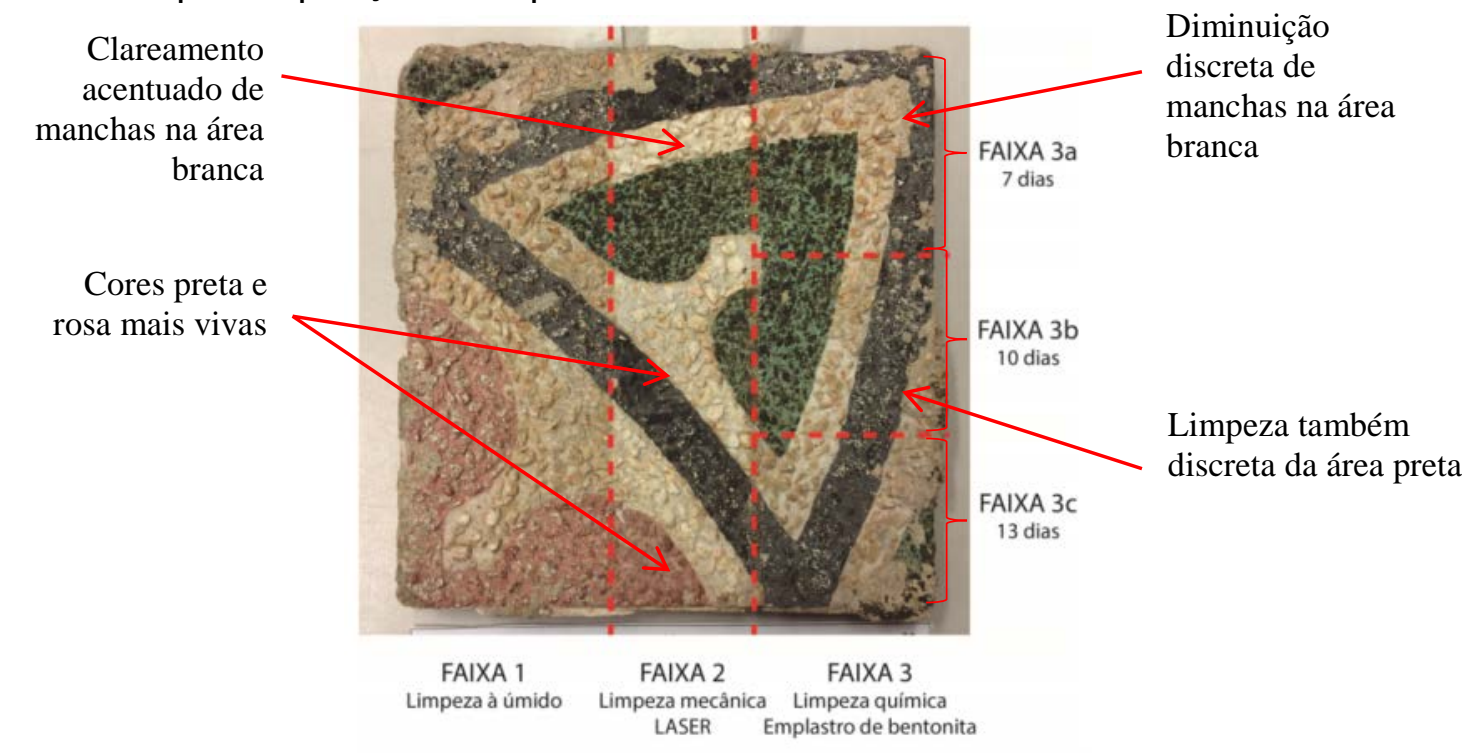

Tabela 2 - Resultados dos testes de brilho na amostra VB-01

\begin{tabular}{c|c|c|c}
\hline $\begin{array}{c}\text { Amostra } \\
\text { VB-01 }\end{array}$ & $\begin{array}{c}\text { Antes dos } \\
\text { procedimentos (ub) }\end{array}$ & $\begin{array}{c}\text { Após limpeza por via } \\
\text { úmida (ub) }\end{array}$ & $\begin{array}{c}\text { Após limpeza química e } \\
\text { mecânica (ub) }\end{array}$ \\
\hline Faixa 1 & 0,253 & 0,260 & - \\
Faixa 2 & 0,257 & 0,367 & 0,42 \\
Faixa 3 & 0,247 & 0,327 & 0,367 \\
\hline
\end{tabular}

Na amostra VB-02, apenas a faixa 3 apresentou aumento dos índices de brilho: 7,14\% após a limpeza por via úmida. As faixas 1 e 2 apresentaram queda dos índices em 9,26\% e em 13,04\% respectivamente (Tabela 3). Após a limpeza química e mecânica (Figuras 10 e 11), a faixa 2 manteve queda acumulada de 26,09\%, com aplicação do laser. Já a faixa 3 manteve o aumento observado acumulado em 28,57\% com a aplicação do emplastro de bentonita.

Na amostra VB-03, as faixas 2 e 3 apresentaram queda dos índices de brilho após todos os procedimentos testados (Tabela 4): 3,11\% e 6,25\% após a limpeza por via úmida e acumulado de 27,46\% e 16,56\% após a limpeza física e química respectivamente. A faixa 1 apresentou aumento de 3,98\% dos índices de brilho após a limpeza por via úmida. De modo geral, assim como Carmona-Quiroga et al. (2010), as medições mostraram que o brilho dos produtos varia sem aparente relação de dependência com outras verificações. Entretanto, com a aplicação de bentonita e com a limpeza por via úmida houve aumento do brilho em dois terços das amostras, enquanto com a aplicação do laser os índices de brilho diminuíram em sua maioria. Estudos mostram que longos pulsos induzem alteração nos objetos - nos metais, por exemplo, causa fusão -, enquanto pulsos curtos são preferíveis (PINI et al., 2000). O tratamento a laser, com irradiação a $1.064 \mathrm{~nm}$, causa grandes perdas de massa em granitos (POZO-ANTONIO et al., 2016) e alteração de cor em objetos metálicos (PALOMAR et al., 2016), fato corroborado pelas alterações de brilho observadas.

Estudos de medição de brilho em argamassas de cal relataram aumento dos índices após impregnação das amostras com consolidantes. Entretanto, o material, também opaco, não atingiu índices de semibrilho (CARMONA-QUIROGA et al., 2010), tal qual as amostras testadas neste trabalho.

Já os resultados dos testes de cor (Tabela 5) demonstraram, na amostra VB-01, que a parte branca apresentou em todas as faixas a maior variação cromática identificada em todos os procedimentos avaliados, com pico de 17,26 unidades na faixa 2. A menor variação de cor ocorreu na área rosa da faixa 2. Conforme diagnóstico, a amostra citada apresentou pior estado de conservação com relação às demais. As variações cromáticas, entretanto, indicaram eficiência na limpeza por via úmida aplicada no ladrilho. Após os procedimentos, a cor branca na faixa de aplicação do laser apresentou maior variação de cor positiva, o que corrobora os resultados identificados no mapeamento. 
A cor branca apresentou aumento do $\Delta \mathrm{E}$ nas intervenções a laser, fato constatado em todas as amostras. As áreas com a cor rosa tiveram seu $\Delta \mathrm{E}$ elevado em todas as amostras. Para Carmona-Quiroga et al. (2010), em produtos à base de cal, alguns tipos de consolidante (Tegosivin HL 100) escureceram as amostras. Já as alterações do $\Delta \mathrm{E}$ para o branco indicam o clareamento da amostra.

A amostra VB-02 (Tabela 6) apresentou pico de variação cromática na faixa 2, na cor branca, tal como ocorreu com a amostra VB-01. Após a aplicação do laser, porém, as variações nas cores branca e rosa foram acentuadas em comparação às demais - 11,45 un e 19,87 un respectivamente. Os resultados cromáticos ratificam o desempenho discreto obtido pela aplicação de emplastro de bentonita identificado no mapeamento. Outros estudos utilizaram emplastros de celulose, que apresentaram resultados satisfatórios, porém também discretos (VEIGA; TAVARES; MAGALHÃES, 2007). A cor verde, entretanto, apresentou melhores resultados com a aplicação do emplastro, tanto na amostra VB-02 como na amostra VB-03.

A amostra VB-03 (Tabela 7) apresentou a menor variação cromática na faixa 2, cor branca, com 0,501 un, após a limpeza por via úmida. O pico cromático da amostra, assim como seus maiores valores, foi aferido na cor rosa, na faixa 2, com 22,1 un.

Tabela 3 - Resultados dos testes de brilho na amostra VB-02

\begin{tabular}{c|c|c|c}
\hline $\begin{array}{c}\text { Amostra } \\
\text { VB-02 }\end{array}$ & $\begin{array}{c}\text { Antes dos } \\
\text { procedimentos (ub) }\end{array}$ & $\begin{array}{c}\text { Após limpeza por via } \\
\text { úmida (ub) }\end{array}$ & $\begin{array}{c}\text { Após limpeza química e } \\
\text { mecânica (ub) }\end{array}$ \\
\hline Faixa 1 & 0,367 & 0,333 & - \\
Faixa 2 & 0,207 & 0,180 & 0,153 \\
Faixa 3 & 0,280 & 0,300 & 0,36 \\
\hline
\end{tabular}

Tabela 4 - Resultados dos testes de brilho na amostra VB-03

\begin{tabular}{c|c|c|c}
\hline $\begin{array}{c}\text { Amostra } \\
\text { VB-03 }\end{array}$ & $\begin{array}{c}\text { Antes dos } \\
\text { procedimentos (ub) }\end{array}$ & $\begin{array}{c}\text { Após limpeza por via } \\
\text { úmida (ub) }\end{array}$ & $\begin{array}{c}\text { Após limpeza química e } \\
\text { mecânica (ub) }\end{array}$ \\
\hline Faixa 1 & 0,327 & 0,340 & - \\
Faixa 2 & 0,193 & 0,187 & 0,14 \\
Faixa 3 & 0,320 & 0,300 & 0,267 \\
\hline
\end{tabular}

Tabela 5 - Resultados dos testes de colorimetria da amostra VB-01

\begin{tabular}{c|c|c|c|c|c|c|c}
\hline $\begin{array}{c}\text { Amostra } \\
\text { VB-01 }\end{array}$ & \multicolumn{2}{|c|}{$\begin{array}{c}\text { Antes dos } \\
\text { procedimentos/Após } \\
\text { limpeza prévia }\end{array}$} & $\begin{array}{c}\text { Após limpeza } \\
\text { prévia/Aplicação de } \\
\text { laser-bentonita }\end{array}$ & $\begin{array}{c}\text { Antes dos procedimentos/ } \\
\text { Aplicação de laser- } \\
\text { bentonita }\end{array}$ \\
\hline Faixa & 1 & 2 & 3 & 2 & 3 & 2 & 3 \\
Branco & 8,43 & 17,26 & 9,94 & 9,06 & 3,53 & 24,25 & 13,22 \\
Rosa & 3,86 & 2,27 & 3,72 & 6,57 & 1,53 & 5,34 & 4,14 \\
Verde 1 & 2,96 & - & 3,30 & - & 1,97 & - & 4,42 \\
Verde 2 & 2,37 & - & & - & - & - & - \\
\hline
\end{tabular}

Tabela 6 - Resultados dos testes de colorimetria da amostra VB-02

\begin{tabular}{|c|c|c|c|c|c|c|c|}
\hline \multirow{2}{*}{$\begin{array}{c}\begin{array}{c}\text { Amostra } \\
\text { VB-02 }\end{array} \\
\text { Faixa }\end{array}$} & \multicolumn{3}{|c|}{$\begin{array}{c}\text { Antes dos } \\
\text { procedimentos/Após limpeza } \\
\text { prévia }\end{array}$} & \multicolumn{2}{|c|}{$\begin{array}{c}\text { Após limpeza } \\
\text { prévia/Aplicação de } \\
\text { laser-bentonita }\end{array}$} & \multicolumn{2}{|c|}{$\begin{array}{l}\text { Antes dos procedimentos/ } \\
\text { Aplicação de laser-bentonita }\end{array}$} \\
\hline & 1 & 2 & 3 & 2 & 3 & 2 & 3 \\
\hline Branco & 1,14 & 3,44 & 1,32 & 8,28 & 1,85 & 11,45 & 3,09 \\
\hline Verde & - & 1,66 & 1,05 & 0,41 & 1,15 & 1,89 & 2,14 \\
\hline Preto & 0,70 & 0,81 & 1,04 & 8,18 & 1,59 & 7,87 & 2,51 \\
\hline Rosa & 0,82 & 0,67 & - & 20,41 & - & 19,87 & - \\
\hline
\end{tabular}


Tabela 7 - Resultados dos testes de colorimetria da amostra VB-03

\begin{tabular}{c|c|c|c|c|c|c|c}
\hline $\begin{array}{c}\text { Amostra } \\
\text { VB-03 }\end{array}$ & \multicolumn{3}{|c|}{$\begin{array}{c}\text { Antes dos } \\
\text { procedimentos/Após limpeza } \\
\text { prévia }\end{array}$} & $\begin{array}{c}\text { Após limpeza } \\
\text { prévia/Aplicação de } \\
\text { laser-bentonita }\end{array}$ & $\begin{array}{c}\text { Antes dos procedimentos/ } \\
\text { Aplicação de laser- } \\
\text { bentonita }\end{array}$ \\
\hline Faixa & 1 & 2 & 3 & 2 & 3 & 2 & 3 \\
Branco & 0,62 & 0,50 & 2,12 & 6,49 & 3,61 & 6,81 & 5,68 \\
Verde & - & 1,32 & 3,71 & 0,79 & 1,72 & 1,17 & 5,40 \\
Preto & 2,82 & 4,20 & 1,04 & 12,27 & 2,60 & 9,21 & 1,61 \\
Rosa & 0,96 & 1,47 & - & 23,07 & - & 22,10 & - \\
\hline
\end{tabular}

\section{Conclusão}

A limpeza por via úmida, com sabão neutro, é adequada e remove depósitos de sujidade superficiais, constituindo-se na primeira ação recomendada para utilização cotidiana na conservação de ladrilhos de marmorite.

A limpeza química com a utilização de emplastro de bentonita mostrou-se satisfatória na remoção de sujidades superficiais, indicada pela variação de $\Delta \mathrm{E}$ nas medições de cor. Entretanto, sua eficácia foi superior à do laser no tratamento da cor verde. Acredita-se que o emplastro é eficaz no aspecto geral da amostra.

Já a limpeza mecânica a laser destacou-se como a mais eficiente, pois removeu manchas persistentes e melhorou o aspecto geral do ladrilho, com o clareamento da matriz cimentícia, também em processo de deterioração. A variação de $\Delta \mathrm{E}$ evidente nas cores branca, preta e rosa tornou as cores mais vivas.

Entretanto, os índices de brilho reduziram-se acentuadamente com a aplicação do laser, causando a opacificação das amostras e demonstrando que o pulso escolhido para as aplicações é determinante nos resultados.

Tais resultados referem-se aos primeiros estudos de aplicação da limpeza a laser em ladrilhos de marmorite. A pesquisa visa iniciar os testes para que, posteriormente, a técnica torne-se viável para outros produtos com essa matéria-prima, assim como em outros materiais de origem calcária e/ou cimentícia.

O emplastro de bentonita e a limpeza por via úmida aumentaram os índices de brilho em dois terços dos casos, o que indica que são medidas menos invasivas à microestrutura do material. Sugere-se que, após a aplicação do laser, haja polimento dos ladrilhos para minimizar as alterações originadas no brilho do material.

\section{Referências}

CARMONA-QUIROGA, P. M. et al. Surface water repellent-mediated change in lime mortar colour and gloss. Construction and Building Materials, p. 2188-21931, 2010.

CHABBI, A. Restoring a 20th century terrazzo pavement: a conservation study of the floor map of the New York State Pavilion, Queens, New York. Pennsylvvania, 2004. Dissertação (Mestrado em Preservação Histórica) - University of Pennsylvania, Pennsylvania, 2004.

COOPER, M. Laser cleaning of sculpture, monuments and architectural detail. Journal of Architectural Conservation, v. 11, p. 105-119, 2005.

GRANDINETTI, S. R. L. Conoscere la graniglia: manuale técnico informativo. 2015. Disponível em: www.grandinetti.it. Acesso em: 10 abr. 2015.

IN SITU - CONSERVAÇÃO DE BENS CULTURAIS. Conservação e restauro de marmorite e elementos pétreos nas fachadas do edifício principal do LNEC. Lisboa. Insitu, 2006. Disponível em:

http://www.insitu.pt. Acesso em: 15 jun. 2014.

KONITA MINOLTA SENSING AMERICAS. Entendendo o espaço de cor L*a*b. 2016. Disponível em: http://sensing.konicaminolta.com.br/2013/11/entendendo-o-espaco-de-cor-lab/. Acesso em: 5 ago. 2016.

LOUREIRO, A. M. S. Argamassas para dessalinização de alvenaria mista de edifício histórico de Belém. Belém, 2013. Dissertação (Mestrado em Arquitetura e Urbanismo) - Programa de Pós-Graduação em Arquitetura e Urbanismo, Universidade Federal do Pará, Belém, 2013.

LUZ, A. B.; OLIVEIRA, C. H. Argila: bentonita. In: LUZ, A. B.; LINS, F. A. F. (org.). Rochas e minerais industriais. 2. ed. Rio de Janeiro: Cetem, MCT, 2008. 
LYNTON LASERS LTD. Laser cleaning: laser cleaning in conservation. Disponível em: http://www.conservationLasers.com/Laser-cleaning/4533647284. Acesso em: 27 set. 2016.

MARTINHO, C.; VEIGA, R.; FARIA, P. Marmorite: contributo para a correta conservação deste durável revestimento de paredes. Conservar Património, Lisboa, v. 28, p. 31-38, 2018.

NATIONAL TERRAZZO \& MOSAICS ASSOCIATION. A brief history fo Terrazzo. The National Terrazzo \& Mosaics Association. 2014. Disponível em: http://ntma.com/literature/. Acesso em: 25 jul. 2015.

OLIVEIRA, M. M. D. Tecnologia da conservação e da restauração: materiais e estruturas: um roteiro de estudos. 4. ed. Salvador: Edufba, 2011.

PALOMAR, T. et al. Evaluation of laser cleaning for the restoration of tarnished silver artifacts. Applied Surface Science, p. 118-127, jun. 2016.

PINI, R. et al. Tests of laser cleaning on archeological metal artefacts. Journal of Cultural Heritage, p. S129-S137, aug. 2000.

POZO-ANTONIO, J. S. et al. Effectiveness of chemical, mechanical and laser cleaning methods of sulphated black crusts developed on granite. Construction and Building Materials, p. 682-690, jun. 2016.

ROYO, J. M. M.; CARRASCOSA, S. B.; DE LA MORENA, C. M. Recomendaciones Técnicas para la Reducción de Patologías en el Terrazo. Revista Informes de la Construcción, p. 57-63, mar. 1998.

VEIGA, R.; TAVARES, M.; MAGALHÃES, A. C. Restauro da fachada em marmorite de cal do Laboratório Nacional de Engenharia Civil, em Lisboa: materiais, métodos e resultados. In: SEMINÁRIO BRASILEIRO DE TECNOLOGIA DE ARGAMASSAS, 7., Recife, 2007. Anais [...] Recife, 2007.

Brena Tavares Bessa

Universidade Federal do Pará | Rua Augusto Corrêa, 1 | Belém - PA - Brasil | CEP 66075-110 | Tel: (91) 3201-8860 | E-mail: brena.bessa@gmail.com

Thais Alessandra Bastos Caminha Sanjad

Universidade Federal do Pará | E-mail: sanj adthais@gmail.com

Carolina de Souza Leão Macieira Gester

Universidade Federal do Pará | E-mail: carolmgester@gmail.com

\section{Ambiente Construído}

Revista da Associação Nacional de Tecnologia do Ambiente Construído

Av. Osvaldo Aranha, 99 - 3o andar, Centro

Porto Alegre - RS - Brasil CEP $90035-190$

Telefone: +55 (51) 3308-4084

Fax: +55 (51) 3308-4054

www. seer. ufrgs. br/ ambienteconstruido

E-mail: ambienteconstruido@ufrgs.br 